\title{
MÉTODOS PARA A INSTRUÇÃO DA CRIANÇA NA PROVÍNCIA DA BAHIA DURANTE O IMPÉRIO
}

\author{
Isabel Cristina de Jesus Brandão \\ Universidade Estadual do Sudoeste da Bahia-UESB
}

\section{RESUMO}

O presente trabalho analisa os métodos para a instrução da criança na Província da Bahia durante o Império. Constitui-se em uma pesquisa qualitativa, tendo como metodologia a análise documental. Foram analisados os relatórios dos Presidentes da Província da Bahia, bem como jornais e revistas do período pesquisado. Os dados indicam que o projeto de instrução que se desenvolvia na escola primária tinha como objetivo principal a moralização das crianças, por meio da qual se buscava formar um indivíduo que atendesse a uma sociedade em pleno desenvolvimento da burguesia e expansão do sistema capitalista, que exigia um povo civilizado de acordo com o modelo europeu de sociedade e civilização que definia os padrões da época. Nesse sentido, o mestre que iria instruir as crianças também deveria ter uma formação que contemplasse os princípios de moralidade e a Escola Normal foi a instituição responsável por essa formação e, também, designada para instruir os futuros mestres na aplicação dos métodos de instrução que predominaram durante o Império: Método Mútuo; Método Lancasteriano; e o Método Simultâneo.

Palavras-chave: Império, Educação, Métodos de Instrução

\section{METHODS OF INSTRUCTION IN THE PROVINCE OF BAHIA DURING THE EMPIRE}

\begin{abstract}
This paper analyses the methods of children's instruction in the Province of Bahia during the Empire in Brazil. It is a qualitative research that used the documental analysis as its methodology. We analyzed reports made by the presidents of the Province of Bahia as well as newspapers and magazines from the given period. The data indicates that the instruction project developed in primary school had the moralization of children as its main objective by which they aimed to form an individual integrated to a society where the bourgeoisie was developing and the capitalistic system was expanding and that required a civilized people according to the European model of society and civilization. Therefore, the master that would instruct the children should also be instructed according to a certain moral standard and the "Escola Normal" (the teacher training school) was the institution responsible for that instruction, as well as training the future masters in applying the prevailing methods of instruction during the Empire: Mutual method ; Lancasterian method ; and Simultaneous Method.
\end{abstract}

Keywords: Empire, Education, Methods of Instruction 
Nesse trabalho analiso os métodos para a instrução da criança na Província da Bahia durante o Império.

Constitui-se em uma pesquisa qualitativa, tendo como metodologia a análise documental compreendendo as fontes como produção e construção histórica do homem, que refletem as relações estabelecidas entre esse homem e o mundo material em que ele se encontra. Além disso, compreende-se que uma adequada análise histórica deve considerar que os acontecimentos possuem uma materialidade objetiva e subjetiva e, por isso, a construção do conhecimento histórico é determinada pelo esforço de abstração e teorização do movimento dialético da realidade. Foram analisados os relatórios dos Presidentes da Província da Bahia, bem como jornais e revistas do período pesquisado. Para Del Priore (2000, p. 15), "resgatar esse passado significa, primeiramente, dar voz aos documentos históricos, perquirindo-os nas suas menores marcas, exumando-os nas suas informações mais concretas ou mais modestas, iluminando as lembranças mais apagadas".

Compreendo que, ao fazer uma pesquisa histórica, devemos ter consciência de que o objetivo é encontrar dados que expressem informações sobre o período estudado em diferentes aspectos: político, econômico e social. "No entanto, a tarefa de produzir o conhecimento histórico torna-se mais complexa na medida em que se tomam como objeto de estudo os processos históricos apreendidos em seus aspectos de totalidade histórica, e não como fatos particulares analisados de forma isolada." (NORONHA, O., 1998, p. 24).

Uma adequada análise histórica deve considerar que os acontecimentos possuem uma materialidade objetiva e subjetiva e, por isso, a construção do conhecimento histórico é determinada pelo esforço de abstração e teorização do movimento dialético da realidade. Esse é o grande desafio na pesquisa com fontes primárias: classificar o que é essencial no processo de garimpagem. Sanfelice (2004, p. 98) compreende que o recorte não tem por objetivo isolar o objeto de estudo, mas que é “[...] apenas oportuno no sentido de privilegiar a análise de um objeto específico e não no sentido de isolamento do mesmo objeto [...]". O pesquisador precisa estabelecer um diálogo com as fontes na tentativa de compreender o objeto de estudo, problematizando a realidade em que este foi produzido.

Nesse sentido é importante destacar que analisar os métodos de instrução utilizado na educação da criança durante o Império exige que compreendamos o papel desempenhado pela Escola Normal nesse contexto, uma vez que cabia a esta instituição formar os professores da época.

Em 1856, quando foi diretor da Instrução, Abílio já reconhecia a importância e o significado dessa instituição:

[...] a Eschola Normal é o verdadeiro centro da instrucção primaria da Provincia, os futuros Professores recebem as inspirações e doutrinas que devem ao depois ir propagar em suas aulas: - ella pois tem em si de algum modo os destinos futuros da Provincia: - e pois aos seus dignos Lentes está destinada em nossa historia uma pagina que espero será brilhante e honroza. (BAHIA, 1856, p. 48). ${ }^{1}$

Sobre a formação de professores, o presidente João Mauricio Wanderley faz a seguinte observação:

Toda a instrucção que se poder dar aos alumnos mestres he pouca, porque elles se destinam á exercer um sacerdócio muito importante, tendo de ficar á testa da instrucção primaria e da educação moral e religiosa da mocidade. O professor primario, como prescreve uma lei da Prussia, deve ter piedade e sabedoria, e penetrar-se de sua alta missão, conhecendo as 
obrigações que ella lhe impõem, deve ter a arte de ensinar e conduzir a mocidade, ser firme na fidelidade com que deve servir ao estado, consciencioso nos deveres de seu emprego, benigno e circumspecto em suas relações com os Paes dos alumnos, e com todos os cidadãos em geral. A instrucção destes deveres he que constitue a pedagogia ensinada em algumas, porem poucas, escolas normaes da Europa. A França, que desde 1830 possue escolas normaes, só em cinco tinha o curso de pedagogia, e apenas a de Strasbourg merecia nesta materia elogios dos homens que tem estudado os progressos da instrucção primaria desse illustrado paiz. Convém por tanto dar toda attenção ao ensino pratico da escola normal para formar bons professores. (BAHIA, 1853, p. 29-30).

Desde sua criação, a escola normal caracterizou-se como a instituição de excelência para capacitação e formação de professores, como nos diz Rocha:

[...] A história da Escola Normal mantém uma estreita relação com a implementação da instrução pública, mais especificamente com a instrucção primária, uma vez que a criação dessas instituições tinha por fim preparar os mestres para as escolas de primeiras letras. Como é sabido, a escola pública, reinventada no mundo moderno, tem na Escola Normal e na escola primária seus pilares básicos. Os sistemas públicos estatais de ensino aparecem configurados de forma já bem definida no século XIX europeu e norte-americano. O Brasil refletiu essas idéias e propostas em outro contexto. (ROCHA, 2008, p. 47).

As primeiras escolas normais no Brasil foram fundadas a partir da década de 1830 (período regencial) e se expandiram nas últimas décadas desse mesmo século. A primeira instituição foi criada em Niterói, em 1835.

A Escola Normal da Bahia foi criada pela Lei $n^{\circ} 37$, de 14 de abril de 1836, sancionada pelo presidente Francisco de Souza Paraíso, mas só veio a funcionar depois de seis anos, em 1842. Segundo o presidente Alvaro Tiberio de Moncorvo e Lima:

[...] posta em exercicio no anno de 1842, tem inquestionavelmente prestado alguns serviços ao ensino primario; e é sem duvida á ella devida em grande parte a gloria de nos acharmos superiores á qualquer das Provincias do Imperio no que respeita á este ramo do serviço publico -. E si mais não tem feito esta Eschola, como era para esperar das habilitações e talentos dos Professores que a compôem, depende isto quasi unicamente da pouca ou nenhuma preparação com que alli se apresentam os aspirantes ao magisterio primario, os quaes na generalidade, não conhecendo sequer os rudimentos da grammatica da lingua vernacula, bem pouco podem aproveitar dos respectivos cursos.

[...]

Não obstante porem a Eschola Normal tem prestado relevantes serviços á Provincia: -muitos alumnos tem dalli sahido convenientemente habilitados; e todos conservam sempre alguma parte das doutrinas que ouviram, e vão por consequencia exercer o magisterio com muito maior proveito para a infancia, de que si a não tivessem cursado. (BAHIA, 1856, p. 43-44).

Havia também um entendimento de que "o funcionamento e a expansão do próprio ensino secundário no país, fosse ele público ou privado, estavam na dependência dessas 
Escolas Normais, já que inexistiam cursos superiores destinados ou adequados à formação de professores [...]" (XAVIER, 1994, p. 85).

As escolas normais foram, também, designadas para instruir os futuros mestres na aplicação do método de ensino mútuo, determinado pela Lei de 1827, conforme podemos observar no relato do presidente do Conselho de Instrução Pública Justiniano da Silva Gomes:

[...] comprehendia duas cadeiras $-1^{\text {a }}$ a de ensino mutuo, na qual se ensinaria praticamente este methodo; $2^{\mathrm{a}}$ a de leitura de Calligraphia, Arithmetica, Desenho linear, principios da Religião Christã, Grammatica philosophica com exercicios de analyse, e imitação dos classicos. A primeira cadeira era exercida por um Professor e um Monitor; porem pelo artigo 8 da Lei n. 172 o Professor do ensino mutuo, Director da escola, he obrigada a dar lições do ensino simultâneo [...] (BAHIA, 1846, p. 36-37).

Mas em que consiste esse método de ensino? Consiste na instrução dos alunos com o auxílio de outro aluno do mesmo nível de conhecimento. O professor desempenha o papel central de observador, enquanto os alunos "ensinam e aprendem". É importante destacar que o principal agente desse processo é o monitor (instrutor), ou seja, um aluno escolhido por se destacar em uma determinada área do conhecimento. O programa de ensino consiste de leitura, escrita e aritmética. Sobre isso observa o relato do professor Antonio Gentil Ibirapitanga sobre processo de ensino da escrita pelo método mútuo, aplicado na Aula de Primeiras Letras da Casa Pia dos Órfãos na província da Bahia:

\section{Instrucção Primaria.}

Na longa pratica da Educação da Mocidade encontrei alguns meios de adiantar os meninos na Instrucção primaria, e que tenho pôsto em pratica com feliz successo: e, como disto não faço misterio publico-os para alguem delles se aproveitar, querendo.

\section{Exercicios de Escripta.}

Logo que o menino vae para a escola, deve escrever, sua escripta deve ser em pedra riscada e um instrumento cortante, afim de consevar a altura, largura, e tombado da letra de bastardo; dirigido por um Monitor cuidadoso, e á vista de um traslado escreverá $\mathrm{U}, \mathrm{N}, \mathrm{O}, \mathrm{A}$, e as mais letras sem haste dentro dos regrados para ir-se acostumando a altura, largura, e tombado da letra; logo que estiver desembaraçado, fará as letras hasteadas, e finalmente o Abecedario todo até fazel-o bem feito; prefiro a pedra, primeiramente para poupar papel; em segundo lugar, porque o menino pode apagar a letra não a achando bem feita, o que muito aproveita.

Passará depois a escrever em papel riscado á lapes da mesma forma que a pedra, (no que dou nome de pautado) aprendendo então a dar a grossura conveniente da letra e suas voltas finas; sem que o menino escreva boas letras, não deve passar adiante; depois escrevera o mesmo abecedario sem o pautado somente com o regrado da altura da letra, sempre á vista de um traslado ou exemplar, que será substituido por outro de bastardo, variando sempre de traslados da mesma letra afim de não decoral-os, e elle ter necessidade de olhar muitas vezes para o exemplar. Conseguido do menino um bom bastardo, (ainda que leve algum tempo) vae-se-lhe 
diminuindo progressivamente a letra até cursivo; e escreverá bem, necessariamente. As pessoas, que tem visitado a Aula de $1 .{ }^{\text {as }}$ Letras na Caza Pia dos Orfãos tem notado, que todos escrevem bem, resultado deste methodo.

$[\ldots]$

O que venho de expor, não são meras theorias, são resultados de longa pratica.

Antonio Gentil Ibirapitanga.

(JORNAL O MENTOR DA INFANCIA, n. 6, 1846, p. 3-4).

Sobre o método mútuo, Bastos (2005, p. 36) destaca que "O professor, antes do início da aula, dá uma explicação especial e indicações particulares. Quando os demais alunos chegam à escola e tomam seus lugares, o monitor de cada classe transmite aos colegas os conhecimentos que lhe foram dados pelo professor. [...]".

Esse método foi desenvolvido por André Bell, médico e pastor anglicano, no século XVIII, ao dirigir um orfanato nas Índias inglesas, em Madras. Para solucionar o problema de contratação de professores, decidiu "utilizar os melhores alunos - os monitores - para transmitir aos demais alunos os conhecimentos que haviam aprendido com o professor. [...]" (BASTOS, 2005, p. 35).

Percurso semelhante teve Joseph Lancaster em Londres ao fundar, em 1798, uma escola para crianças pobres. Também por dificuldades em contratar mais professores, implementou um projeto de ensino semelhante ao de Andrew Bell, porém acrescentou a supervisão imediata do professor no trabalho desenvolvido pelos monitores. Segundo Bastos,

Lancaster percebeu que, por esse método, um só professor era suficiente para dirigir, com ordem e facilidade, uma escola de quinhentos e até mil alunos. Publicou Améioration dans l'education dês classes industrieuses de la société, onde destaca os resultados obtidos, estimulando a abertura de inúmeras escolas que imitam o método de Lancaster. (BASTOS, 2005, p. 35-36, grifo do autor).

Segundo Manacorda,

[...] a sistematização didática rigorosa e a difusão em vista de um plano nacional de instrução popular começou (discute-se quanto à precedência) por obra do pastor anglicano Andrew Bell (1753-1832), que, a partir de 1789, dirigiu em Madras uma escola instituída pela Companhia das Índias Orientais para os filhos de seus soldados europeus, e por obra do quaker Joseph Lancaster (1778-1838), que em 1798 abriu em Londres uma escola para crianças pobres. (MANACORDA, 2004, p. 257).

Inicialmente, o método mútuo foi divulgado no Brasil, de acordo com Silva (2008, p. 52), por "estudantes brasileiros que retornavam da Europa e, também, da publicidade de alguns órgãos da imprensa publicados por brasileiros no velho continente como $O$ Observador Brasileiro em Londres de Hipólito José da Costa" (grifo do autor).

Essa proposta metodológica atendeu com eficiência um dos princípios do projeto liberal, o da "educação para todos" e, o mais importante, com baixos investimentos. Acreditamos que este tenha sido o principal motivo de sua expansão. Na Inglaterra, foi aplicado "[...] para atender às exigências da expansão rápida do ensino público elementar, segundo as necessidades geradas lá pela industrialização" (XAVIER, 1994, p. 64). Para 
Manacorda (2004, p. 258), o ensino mútuo não é somente um método didático, “mas em primeiro lugar [de] uma opção política, sujeita a encontrar consensos e dissensos". Ele destaca as observações feitas por José Hamel, pedagogo alemão que difundiu o método na Europa,

Convém ou não difundir a instrução no mundo? Devemos ou não desejar que as classes inferiores da sociedade recebam pelo menos os princípios de uma instrução elementar?"

Havia, de fato, ainda "quem sustente que é melhor recusar qualquer educação às classes inferiores da sociedade, do que expô-las a descobrir com dor sua situação e a perturbar o status quo para sair dele. (HAMEL apud MANACORDA, 2004, p. 258).

Compreende que "o ensino mútuo era a resposta prática a este perpétuo medo dos conservadores, o medo de que a instrução pudesse "perturbar o Estado" (MANACORDA, 2004, p. 258).

Em 1830, existiam na Bahia seis instituições que ministravam o ensino mútuo, conforme informações do presidente Luiz Paulo de Araujo Basto:

[...] Prospéra igualmente quanto he possivel a Provincia na instrucção; só dentro da Capital ha quatro Collegios de educação, a saber o dos Orfãos, e tres particulares, desesete Aulas publicas de estudos preparatorios, desenove ditas particulares, sendo o maior numero destas nos Collegios, vinte e tres Aulas publicas de Primeiras Letras, vinte e duas ditas particulares; entre as Aulas publicas ha ja duas, que ensinão perfeitamente pelo Systema de ensino mutuo, tres entre as particulares: ha mais o Collegio Medico Cirurgico. O numero em todas as Aulas he de dois mil quinhentos e trinta e cinco, em que ha augmento comparativamente com os alumnos, que as frequentavão no anno passado, especialmente quanto ao sexo feminino. (BAHIA, 1830, p. 1, grifo nosso).

Para Gilberto Alves, um dos fatores relevantes do ensino mútuo é que a

sua utilização, objetivamente, revestiu-se de um caráter transitório, pois emergiu como decorrência de uma formidável demanda por serviços escolares, quando eram precários os recursos para atendê-la, daí a necessidade de dar-lhes aproveitamento máximo. O ensino mútuo procurou responder, portanto, a uma necessidade histórica precisa. Por isso, ao revelar-se como solução precária, no interior de uma conjuntura educacional que reclamava a extensão dos serviços escolares para todos, de mecanismo de ação adaptado às condições vigentes tornou-se, ele próprio, característica expressiva dessa conjuntura marcada pela carência. A superação de tal conjuntura, necessariamente, implicaria sua própria superação (ALVES, 2006, p. 117).

Esse autor chama a atenção para o fato de que "ao longo do século XIX, ocorreu uma tendência de progressiva desqualificação do ensino mútuo". (ALVES, 2006, p. 119). As críticas não levavam em consideração as reais condições educacionais para implementação de projetos pedagógicos e a falta de uma política pública para a educação durante o Império. 
É expressivo que, ainda no final do período imperial, o primeiro sistematizador de uma interpretação histórica da educação brasileira, José Ricardo Pires de Almeida, não tenha se posicionado contra o ensino mútuo. Mesmo registrando as pioneiras manifestações de frustração de autoridades brasileiras com os resultados alcançados por esse "sistema de instrução primária”, sua própria avaliação não o desqualificava. Reconheceu ter sido uma "ilusão" a tentativa dos "liberais de difundir o ensino mútuo em todos os recantos da jovem nação". Afinal, "faltava pessoal e o Estado tanto como as municipalidades não podiam fazer grandes sacrifícios orçamentários, no início de organização de um vasto Império". Essa premissa de sua interpretação opunha-se às superficiais considerações de deputados e de ministros do Império, que jamais tocavam as determinações dos pífios resultados educacionais obtidos. [...] (ALVES, 2006, p. 134).

Uma das questões que chamam a atenção no método de ensino é a distribuição do tempo, sobre o que Focault se posiciona da seguinte forma:

No começo do século XIX, serão propostos para a escola mútua horários como o seguinte: 8,45 entrada do monitor, 8,52 chamada do monitor, 8,56 entrada das crianças e oração, 9 horas entrada nos bancos, 9,04 primeira lousa, 9,08 fim do ditado, 9,12 segunda lousa, etc. A extensão progressiva dos assalariados acarreta por seu lado um quadriculamento cerrado do tempo [...] (FOUCAULT, 2000, p. 128).

E ainda: "o tempo medido e pago deve ser também um tempo sem impureza nem defeito, um tempo de boa qualidade, e durante todo o seu transcurso o corpo deve ficar aplicado a seu exercício. A exatidão e a aplicação são, com a regularidade, as virtudes fundamentais do tempo disciplinar. [...]" (FOUCAULT, 2000, p. 129). Observamos que a dinamização na economia do tempo contribuía para a economia nos gastos com a instrução, especialmente porque os monitores não eram remunerados.

No Brasil, o método lancasteriano foi oficializado em 1827, pelo Decreto que regulamentou as Escolas de Primeiras Letras:

Art. $4^{\circ}$ As escolas serão do ensino mútuo nas capitais das províncias; e serão também nas cidades, vilas e lugares populosos delas, em que for possível estabelecerem-se.

Art. $5^{\circ}$ Para as escolas do ensino mútuo se aplicarão os edifícios, que couberem com a suficiência nos lugares delas, arranjando-se com os utensílios necessários à custa da Fazenda Pública e os Professores que não tiverem a necessária instrução deste ensino, irão instruir-se em curto prazo e à custa dos seus ordenados nas escolas das capitais.

Art. $6^{\circ}$ Os professores ensinarão a ler, escrever, as quatro operações de aritmética, prática de quebrados, decimais e proporções, as noções mais gerais de geometria prática, a gramática de língua nacional, e os princípios de moral cristã e da doutrina da religião católica e apostólica romana, proporcionados à compreensão dos meninos; preferindo para as leituras a Constituição do Império e a história do Brasil. (BRASIL, 1827, p. 1). 
Silva (2008), tendo como base o pedido de aposentadoria do professor Lázaro Muniz da Costa, parte do princípio de que esse método começou a ser aplicado na Bahia a partir de 1850.

[...] nesta capital o sistema de Ensino Mutuo na Aula Nacional, que regia na Freguesia de S. Pedro velho onde servio por 19 anos [...] Em 1828 o supplicante recebeo uma Portaria do Governo para ensinar o novo Sistema a todos os Professores da provincia, assim como a todas as Senhoras, que se quisessem propor as cadeiras de meninas, que se hirão crear em virtude da Lei de 15/10/1827 o que tudo satisfez o supplicante gratuitamente tanto que quando se estabeleceo sua Aula Normal com a obrigação de todos os Professores, que existião hirem frequental-a requererão a Assemblea, que já tinham com o supplicante aprendido por ordem do Governo, forão atendidos, e lá não forão, razão esta, por que o supplicante pedia a sua jubilação sem ter os 20 annos. (APEB, Ensino Elementar, 4006, 11/11/1850 apud SILVA, 2008, p. 53).

Mas, por uma série de problemas no sistema de ensino brasileiro, especialmente no que se refere à formação do professor, não teve o sucesso desejado conforme observa o presidente do Conselho de Instrução Pública Justiniano da Silva Gomes:

Nenhum professor, excepto o da Cachoeira, emprega em sua Aula o methodo mutuo, nem mesmo aquelles professores que forão discipulos da Escola Normal, que antes da Lei 172 ensinava exclusivamente o methodo mutuo. Comtudo a Lei 37 no art. 18 modificava para as Escolas o exclusivismo do methodo mutuo determinando-o somente para aquellas Aulas, cuja afluencia de discipulos excedesse de 100. Os professores por mero arbitrio, e á revelia proscreverão este methodo: o de Maragogipe, com mais de 160 discipulos (a Escola a mais numerosa da Provincia) não ensina pelo ensino mutuo. (BAHIA, 1846, p. 51-52).

A partir dos anos 1850, houve reivindicação para implantação do método simultâneo desenvolvido por Castilho ${ }^{2}$ em Portugal, em detrimento do ensino mútuo de influência francesa. Segundo o diretor da Instrução Abílio César Borges,

O methodo - Castilho - que alguns progressos ja tem feito em Portugal, sendo simultaneo parece preferivel ao ensino mutuo. Elle começa pela decomposicção das palavras e leitura auricular, contem a menomonisação por figuras e historias dos caracteres que se podem apresentar aos alumnos, reduzidas a ritmo as historias com frequencia de canto, palmas e marchas para interessar e prender a attenção dos alumnos. [...] (BAHIA, 1854b, p. 8).

Tenho lido o que se tem publicado a este respeito, e creio que o methodo Castilho é uma verdade provada, mas que para ser bem desenvolvida precisa de ser praticamente estudada e applicada por mui intelligentes professores, que muita vez ver-se-hão na necessidade de modificar o ensino segundo a idade, e indole dos alumnos. (BAHIA, 1854, p. 14-15).

Para aprender a usar o novo método, o presidente João Mauricio Wanderley propôs o envio de professores a Portugal: 
Não seria tambem improductiva a despesa que se fizesse com um dos nossos habeis professores publico ou particular que fosse estudar a Portugal o methodo de leitura repentina, inventando pelo distincto litterato Antonio Feliciano de Castilho. O nome do autor é já uma garantia de que um tal invento não é dessas utopias tão communs no seculo em que vivemos. (BAHIA, 1854, p. 14).

Estudos apontam como origem do método simultâneo os trabalhos desenvolvidos por Jean Baptiste de la Salle, no século XVIII, na França. Conhecido como método das Escolas Cristãs, foi exposto na obra Conduite des écoles chrétiennes ${ }^{3}$, redigida em 1702 por La Salle, mas impressa somente em 1720.

Podría pensarse que esta obra venía a ser como la «Regla» de los Hermanos para la escuela, de igual modo que las Reglas Comunes lo eran para la vida comunitaria. Pero el mismo prefacio del manuscrito de 1706 nos aclara esta idea. Dice que el libro no está concebido como regla y que hay muchos puntos que serán difíciles de cumplir, sobre todo a algunos Hermanos. Pero alienta y recomienda que los Hermanos lo observen cuidadosamente, como expresión de la voluntad de Dios, dada por medio de los superiores.

La Guía de las Escuelas tiene un valor pedagógico de primer orden. Aparte de que se haya podido inspirar en otras obras o prácticas existentes en la época, la realidad es que conformó un estilo propio de enseñar y de educar, que caracterizó a las Escuelas Cristianas y que otros muchos pedagogos, algunos de ellos fundadores de institutos docentes, bebieron en ella sus ideas educativas. ${ }^{4}$

Conduite des écoles chrétiennes está dividida em duas partes: na primeira, estão as regras sobre "os exercícios que se fazem nas escolas cristãs e a maneira como se devem fazer" e, na segunda parte, "os meios para manter e estabelecer a ordem" (MANACORDA, 2004, p. 228).

No relatório do diretor da Instrução Abílio César Borges, do ano de 1856, encontrase um quadro comparativo entre os dois métodos de ensino e as causas do fracasso do método mútuo francês. ${ }^{5}$

O modo de ensino mutuo, que não ha muitos annos produziu uma especie de furor, acha-se actualmente sem a minima voga; pois contra elle se ha declarado a experiencia e a razão: - e na verdade, por mais habil e dedicado que seja um Professor, pouco resultado alcançará do ensino mutuo, sendo como é difficilimo encontrar monitores zelosos, perseverantes e graves, como requerem suas funcções. - Na Allemanha, na França, e na Hollanda este modo de ensino está desde muito proscripto, e entre nós não ha um só Professor que o adopte em sua aula, sinão com muitas alterações, e sempre em maxima parte ajudado do simultaneo: - parece mesmo um contra senso o arvorar-se em mestres quem ainda precisa de aprender, fazendo-se de tal modo perder a esses alumnos que servem de monitores o tempo que podiam e deviam empregar em ouvir o Professor, e adiantar os seus conhecimentos.

A experiencia mostrou, e ha de mostrar sempre, diz o Sr Castilho, que as escholas pelo modo mutuo são um arremêdo mais ou menos perfeito de ensino; uns pulvimetros de erros e despropositos, um tiro anticipado de peitas e compadríos, de calumnias e de vinganças. - Os inferiores 
insurgem-se contra a auctoridade absurda e ridicula de quem lhes é por tantas circumstancias igual; os pseudo-doutrinadores vingam-se; os primeiros não aprende, os segundos não ensinam, e alem de não ensinarem, não aprendem tambem, porque estão repetindo a comedia do asinus asinum fricat. - O Professor titular dormita como uma Divindade de Epicuro!

O modo simultaneo ao contrario, para dar excellentes resultados, nada mais requer do que as habilitações e dedicação do Professor, qualidades que são tambem essenciaes no ensino mutuo.

O mestre deve ensinar sempre, e o discipulo sempre aprender: isto só se póde conseguir com o ensino simultaneo. Todavia não posso deixar de confessar que nas escholas muito numerosas o modo simultaneo necessita de pedir algum pequeno auxilio ao mutuo. - É o que está succedendo em algumas grandes escholas desta Capital.

Uma eschola simultanea, diz Mr. Matter, ${ }^{6}$ vale o que valem os mestres que a dirigem; uma eschola mutua, o que valem os monitores que servem de mestres.

Tambem o ensino simultaneo é hoje de preferencia seguido em quase todas as escholas da Europa. (BAHIA, 1856, p. 50-51).

Para reforçar a sua defesa sobre o método de ensino de Castilho, Abílio solicitou parecer da comissão da Sociedade de Ciências Médicas de Lisboa.

\section{Parecer da Commissão da Sociedade de Sciencias Medicas de Lisboa nomeada para dar sua opinião sobre o methodo portuguez do ensino primario do Sr. Castilho, considerado phyziologicamente. Bahia, 28 de novembro de 1855 .}

Senhores.

A vossa Commissão lêu e meditou attentamente a representação, que um dos nossos socios nos dirigia, afim de que esta sociedade, submettendo ao seu exame os processos e as praticas do novo methodo de leitura do Dr. Castilho manifestasse o seu juizo com respeito ás vantagens ou desvantagens do mesmo methodo sobre o antigo debaixo do ponto de vista hygienico e physiologico.

A vossa Comissão não podia hesitar na manifestação da sua opinião sobre tão poderoso objecto.

$[\ldots .$.

A vossa Comissão, senhores, não encarou o methodo portuguez sinão debaixo do ponto de vista hygienico e physiologico, e abandonou a outras associações ou individuos a incumbencia de o apreciarem debaixo de outros aspectos.

$[\ldots]$

O methodo do Sr. Castilho tem inquestionavelmente uma grande vantagem physiologica sobre os methodos anteriores. As palmas a marcha e o rythmo são uma especie de engodo para o ensino dos alumnos, estes artifícios são uma pequena seducção que lhes apresenta como um brinquedo pueril o trabalho da instrucção.

O canto e o metro são tambem um grande atractivo para os sentidos, elles incitam e sustentam a capacidade da attenção, que é o grande segredo na arte de ensinar. Estes exercicios continuam a illusão dos alumnos que suppôem em tudo aquillo um continuo jogo. Mas o canto e o metro 
exercitam ao mesmo tempo os orgãos da respiração e da voz, isto é, a caixa do peito, o pulmão e a laringe. (BAHIA, 1856, p. 2).

Os symbolos são ao mesmo tempo grandes meios mnemonicos, e excellentes auxiliares para as intelligencias nascentes. [...] o contentamento dos alumnos no methodo portuguez é tão pronunciado que o desenvolvimento dos orgãos não póde deixar de ganhar muito com esta alegria interior, e com a expansão moral que a acompanha. (BAHIA, 1856, p. 2-3).

As contrariedades continuas azedam pelo contrario as faculdades affectivas, e tornam duro e ás vezes mesmo attrabiliario o caracter; e debaixo deste ponto de vista ainda o methodo do nosso sócio é altamente recommendavel.

Por todos estes motivos entende a vossa commissão que debaixo do ponto de vista hygienico e physiologico é muito preferivel o methodo portuguez aos nossos antigos methodos.

Salla da Commissão em 28 de Novembro de 1855.

Dr. José Maria Grande.

Augusto João de Mesquita.

José Antonio de Arantes Pedroso.

(BAHIA, 1856, p. 1-3).

A instrução simultânea culminaria, mais tarde, na educação em classes individualizadas tais como são conhecidas hoje, como bem relata David Hamilton:

[...]. A instrução simultânea mais antiga (isto é, nos anos 1830) tipicamente tomava a forma de uma lição dada num grande auditório conduzida com um número relativamente grande de alunos (por exemplo, uma "divisão"). Se uma escola tivesse uma sala de aula - uma situação excepcional nos anos 1830 - ela era usada para a instrução individualizada de grupos menores de alunos (por exemplo, uma "classe" ou 'draft'). Por outro lado se houvesse apenas uma sala de aula, o(a) mestre-escola e seus assistentes (se havia algum) conduziam lições 'coletivas' e "individuais" lado a lado na mesma sala. Assim, é importante observar que embora a instrução simultânea possa ser considerada uma forma prévia de ensino de classe, ela não estava associada com salas de aula. Em vez disso, as classes ensinadas em salas de aula continuavam a receber sua instrução "por turnos". De fato, não foi senão até os anos 1860 e 1870 que os professores, salas e classes começaram a convergir numa relação um-a-um. Igualmente, não foi senão até um período posterior que o "ensino de classe" começou a adquirir as conotações que teria no século vinte. (HAMILTON, 1992, p. 11-12).

Para Hamilton, a "mudança do ensino individualizado para o ensino de classe teve alguma coisa a ver com a mudança concomitante da produção 'doméstica' 'para a fabril'[...]"' (HAMILTON, 1992, p. 6).

É importante considerar que houve momentos nas escolas em que os diferentes métodos eram utilizados concomitantemente, como explicita a fala do presidente Francisco Gonçalves Martins: 
Nesta Cidade parecerão-me em bom estado as seguintes aulas de $1^{\text {as }}$ letras. A da Sé frequentada regularmente por 90 alumnos, a de S. Pedro por 85 , a de S. Antonio por 80, a da Calçada por 50. No mesmo estado achei as aulas de meninas que se seguem: a de S. Pedro frequentada por 80 meninas, a da Conceição por 50, a de Santa Anna por 50, a da Penha por 40, e a da Victoria, no Campo grande, por 30. Em nenhuma das aulas que tenho visitado pratica-se o ensino mutuo, nem mesmo exactamente o simultaneo por falta de compendios, e exemplares para todos os alumnos. Ha huma mistura do ensino mutuo, simultaneo, e individual. (BAHIA, 1851, p. 3, grifo nosso).

Muito mais do que as descrições legais, as práticas cotidianas e, até mesmo, o momento de desenvolvimento dos métodos de ensino é que definem as melhores formas. E, ainda, o surgimento de um novo modelo não extingue, necessariamente, pelo menos em curto prazo, o antigo. Sobre isso, assegura Hamilton:

[...] todas as formas pedagógicas - não importa qual seu grau de institucionalização - corporificam "graus de liberdade" que abrem a possibilidade de mudanças subseqüentes. Consciente ou inconscientemente, professores e alunos exploram esses graus de liberdade à medida que trabalha, dia após dia, para efetivar seus próprios objetivos pedagógicos. Por sua vez, estabelece-se uma tendência educacional que, se consolidada, pode culminar no estabelecimento de práticas pedagógicas reconhecidamente alteradas. (HAMILTON, 1992, p. $13)$.

Entre os problemas encontrados pelas autoridades para implementação e funcionamento dos métodos de ensino, destacam-se: a falta de escolas apropriadas e de professores qualificados e a inoperância das escolas normais em instruir os alunos no uso do método.

Segundo o presidente Gordilho de Barbuda:

A Lei de 15 de Outubro de 1827, que manda criar escolas elementares, tem occupado a attenção do Conselho do Governo, e por falta das informações das Camáras, apenas se tratou, e resolveo ácerca da organisação das escolas da Cidade; mas grandes são as dificuldades, que se encontrão em se acharem os edifícios, que são necessarios para se pôr em pratica o methodo Lencasteriano. A este Conselho agora compete em observancia da Lei fixar o numero das que devem mais haver. (BAHIA, 1828 , p. 1-2).

Em 1839, o presidente Thomaz Xavier Garcia de Almeida afirmou:

As aulas primarias, que são em $\mathrm{n}^{\circ}$ de 171 quasi todas são regidas pelo methodo simultaneo, tendo apenas adoptado o Lencasteriano ás desta Cidade, e sua cercania, as da Cidade da Cachoeira e S. Amaro, e Villa de Maragogipe, parecendo ainda pouco consideraveis as vantagens deste ultimo methodo, por falta sem duvida de professores habeis, e capazes de o estabelecer, e dirigir conforme o seo verdadeiro mechanismo, ou por que os tenues ordenados, naõ convidão a quem melhor o poderia desempenhar. (BAHIA, 1839, p. 12). 
Problema vivenciado também na escola normal, conforme analisou o Conselho da Instrução Pública, no relatório de 1846:

[...] a parte pratica do ensino dos methodos naõ tem tido lugar, isto he, esta Escola naõ tem preenchido o fim da Lei, e nem até hoje tem produzido quase um resultado: e se prova que depois da creação da Escola Normal todos os Professores primarios, e muitos sahidos da Escola Normal confessaõ naõ empregarem no seu ensino o methodo mutuo, e nem desempenhaõ inteiramente o programma do artigo $5 .^{\circ}$ da Lei P. n. 172, do qual esta Escola deveria dar a norma. (BAHIA, 1846, p. $37)$.

Os alunos que atuavam como monitores nas escolas de ensino mútuo eram considerados mestres em potencial e, por isso, os governos encontrariam nas escolas primárias os bons mestres para instrução das crianças no caminho da civilização.

[...] da mesma sorte que o diamante e a perola, uma vez achados, precisam de lapidação e polimento para terem maior valia e serem apreciados, assim tambem os individuos de vocação, uma vez descobertos, necessitam de ser limados, facetados, polidos, preparados, emfim, como convém, para o exercicio da mais séria e mais importante das funcções sociaes.

Onde buscal-os, repito, esses entes preciosos, privilegiados?

Como tirar a prova de sua vocação?

Como preparal-os para a investidura do sacerdocio do ensino?

As escolas primarias, senhores, são as minas, onde devem ser de preferencia procuradas as vocações para o magisterio.

E' alli que espontaneamente se revelam os privilegiados possuidores do tão raro quão precioso dom.

Os mestres communs, ainda os menos habeis, senhores, descobrem instintivamente entre os discipulos quaes os dotados de faculdades educativas, e os sabem logo escolher para seus monitores e ajudantes.

Escolas ha, senhores, e eu tenho conhecido algumas em que certos monitores teem mais força moral para manter a ordem entre os condiscipulos do que os proprios mestres.

Os mesmos condiscipulos, consultados sobre quem deva substituir o mestre em alguma ausencia, nunca vacillam em acclamar o que mais dotes educativos tem; e raramente ou nunca erram.

Eis ahi, senhores, as minas em que os Estados podem achar os diamantes e as perolas do ensino; - eis ahi o modo de revelação natural das vocações para o magisterio. (BORGES, 1882, p. 8).

Depois, deveria o futuro mestre ser encaminhado à escola normal, onde iria adquirir a instrução de que necessitaria para ser um verdadeiro mestre no ensino das crianças.

\section{Considerações}

Não podemos desconsiderar que os métodos de ensino adotados na província baiana durante o Império fazia parte de um projeto mais amplo de sociedade no qual a instrução que se desenvolvia na escola primária tinha como objetivo principal a moralização das crianças, por meio da qual se buscava formar um indivíduo que atendesse 
a uma sociedade em pleno desenvolvimento da burguesia e expansão do sistema capitalista, que exigia um povo civilizado de acordo com o modelo europeu de sociedade e civilização que definia os padrões da época.

O ensino tinha muito mais uma conotação de status e, nesse sentido, era destinado, inicialmente, à elite dominante. Porém, à medida que o capitalismo foi adquirindo forma e, consequentemente, exigindo pessoas qualificadas para a sua consolidação, a instrução primária passou a ser direcionada principalmente à formação do trabalhador e a educação, à moralização dos sujeitos.

Nesse sentido a política de educação no Império cumpriu com o seu papel de formar mão-de-obra para o sistema capitalista em ascensão e difundir os conceitos de moralização e civilidade tão necessários para garantir ao Brasil a inserção na nova configuração político-econômico-social. Assim, a educação é compreendida como uma atividade humana social e histórica, que se organiza de forma conflituosa e contraditória, articulada com os múltiplos interesses econômicos, políticos, culturais e sociais e estruturada da maneira como se organiza o processo de produção da existência humana no trabalho.

\section{Referência}

ALVES, Gilberto Luiz. O ensino mútuo e a organização do trabalho didático. In: ALVES, Gilberto Luiz. O trabalho didático na escola moderna: formas históricas. Campinas, SP: Autores Associados, 2006.

BAHIA. Falla do Excellentissimo em o $1^{\circ}$ de dezembro d'este anno, dia em que se instalou nesta cidade o Conselho Geral da Província. Bahia: Typograprhia Imperial e Nacional, 1828 (Presidente Gordilho de Barbuda - Visconde de Camamú) 1830.

.Falla do Presidente Luiz Paulo de Araujo Basto. Bahia: Typ. Imp. Nacional,

Falla que recitou o Presidente da Provincia da Bahia Thomaz Xavier Garcia de Almeida na abertura da Assembléa Legislativa da mesma província em 2 de Fevereiro de 1839. Bahia: Typographia de Manoel Antonio da Silva Serva, 1839.

Relatorio apresentado pelo Concelho de Instrucção Publica, a Assemblea Legislativa da Provincia da Bahia. Bahia: Typographia de Galdino Jose Bizerra e Compa, 1846.

Relatorio sobre o estado da Instrucção Publica da Provincia da Bahia apresentado ao Ex. Dezembargador Conselheiro Francisco Gonçalves Martins presidente da mesma Província, por Casemiro de Sena Madureira no anno de 1851. Bahia: Typographia Const. de Vicente Ribeiro Moreira, 1851.

.Falla que recitou o Exm. Presidente da Provincia da Bahia, o Dr. João Mauricio Wanderley, n'abertura da Assembléa Legislativa da mesma Provincia no 1. de março de 1853. Bahia: Typographia Const. Vicente Ribeiro Moreira, 1853. 
Falla recitada na abertura da Assembléa Legislativa da Bahia, pelo Presidente da Provincia o Doutor. João Mauricio Wanderley no 1. $^{\circ}$ de março de 1854. Bahia: Typographia de Antonio Olavo da França Guerra e Comp., 1854.

Relatorio sobre a Instrucção Publica da Provincia da Bahia apresentado ao $\overline{I_{L L m}}{ }^{\circ}$ e Ex.mo SNR Presidente Commendador Álvaro Tibério de Moncorvo e Lima por Abílio César Borges. Typographia de Antonio Olavo da França Guerra e Comp.,1856.

BASTOS, Maria Helena Câmara. O ensino monitorial/mútuo no Brasil (1827-1854). In: STEPHANOU, Maria; BASTOS, Maria Helena Câmara (orgs.). Histórias e memórias da educação no Brasil. Petrópolis, RJ: Vozes, 2005.

BORGES, Abilio Cesar. Dissertação lida no Congresso Pedagógico Internacional de Buenos Ayres em 2 de maio de 1882. Rio de Janeiro: Typ. A vapor do Cruzeiro, 1882.

BRASIL. Lei de 15 de outubro de 1827. Disponível em: <http://www.neppdh.ufrj.br/educacao_imperio.html>. Acesso em: 25 set. 2008.

DEL PRIORE, Mary (org.). História da criança no Brasil. 2. ed. São Paulo: Contexto, 1991. - (Caminhos da história)

FOUCAULT, Michel. Vigiar e Punir: nascimento da prisão; tradução de Raquel Ramalhete. $22^{\circ}$ ed. Petrópolis: Ed. Vozes, 2000.

HAMILTON, David. Mudança social e mudança pedagógica: a trajetória de uma pesquisa histórica. In: Teoria \& Educação, Porto Alegre: Pannonica Editora, n. 6, p. 3-32, 1992.

JORNAL O MENTOR DA INFANCIA. Bahia: Typographia Guaycurú, n. 2 ., 7 nov. 1846.

MANACORDA, Mario Alighiero. História da educação: da antiguidade aos nossos dias. Tradução de Gaetano Lo Mônaco; revisão da tradução Rosa dos Anjos Oliveira e Paolo Nosella - 11. ed. - São Paulo: Cortez, 2004.

NORONHA, Olinda Maria. História da Educação: sobre as origens do pensamento utilitarista no ensino superior brasileiro. Campinas, SP: Editora Alínea, 1998.

ROCHA, Lúcia Maria da Franca. A Escola Normal na Província da Bahia. In: ARAUJO, José Carlos Souza, FREITAS, Anamaria Gonçalves Bueno de Freitas, LOPES, Antônio e Pádua Carvalho Lopes (orgs.). As escolas normais no Brasil: do Império à República. Campinas, SP: Editora Alínea, 2008.

SANFELICE, José Luis. Fontes e história das políticas educacionais. In: LOMBARDI, José Claudinei e NASCIMENTO, Maria Isabel Moura (orgs.). Fontes, história e historiografia da educação. Campinas, SP: Autores Associados, 2004. (Coleção Memória da Educação). 
SILVA, José Carlos de Araújo. O ensino mútuo e o ensino simultâneo na provincia da Bahia: cotidiano e trabalho docente. In: LUZ, José Augusto e SILVA, José Carlos (orgs). História da Educação na Bahia. Salvador: Arcádia, 2008.

XAVIER, Maria Elizabete Sampaio Prado, RIBEIRO, Maria Luisa Santos, NORONHA, Olinda Maria. História da Educação: a escola no Brasil. São Paulo: FTD, 1994. (Coleção Aprender \& Ensinar)

\footnotetext{
${ }^{1}$ Nas citações reproduz-se a escrita original dos textos da época

2 “António Feliciano de Castilho, primeiro visconde de Castilho (Lisboa, 28 de Janeiro de 1800 - Lisboa, 18 de Junho de 1875), foi um escritor romântico português, polemista e pedagogo, inventor do Método Castilho de leitura.
}

Preocupado com o aterrador analfabetismo da população portuguesa, começou a luta em que empenhou uma grande parte da sua vida. Pretendia fazer adoptar um método de leitura repentina, que denominou o Método Português (depois conhecido como o Método Português de Castilho) de aprendizagem da leitura, contra o qual se levantaram grandes polémicas.

Depois de uma luta pertinaz pela adopção do seu método, e no meio de uma generalizada descrença dos pedagogos sobre a sua eficácia, o governo nomeou-o Comissário para a Propagação do Metodo Português e deu-lhe um lugar no Conselho Superior de Instrução Pública. Contudo, nunca adoptou oficialmente o método para uso generalizado nas escolas públicas, recusa que seria o eterno pesar da vida de Castilho."

Disponível em: <http://pt.wikipedia.org >. Acesso em: 30mai. 2008.

${ }^{3}$ Disponível em <http://www.lasalle.es/matias/delasalle/09_Guia_de_las_Escuelas.pdf.>. Acesso em: 5 out. 2008.

4. Poderia se pensar que esta obra vinha a ser como a "Regra" dos Irmãos para a escola, assim como as Regras comuns eram para a vida comunitária, mas o mesmo prefácio do manuscrito de 1706 esclarece esta idéia. Ele diz que o livro não foi concebido como regra e que há muitos pontos que serão difíceis de cumprir, sobretudo para alguns irmãos. Mas orienta e recomenda que os irmãos o observem cuidadosamente, como expressão da vontade de Deus, dada por meio dos Superiores.

O guia das Escolas tem um valor pedagógico de primeira ordem. Embora possa ter sido inspirado em outras obras ou práticas existentes na época, a realidade é que conformou um estilo próprio de ensinar e de educar, que caracterizou as Escolas Cristãs e outros muitos pedagogos, alguns deles fundadores de institutos docentes, que beberam nele suas idéias educativas. (Tradução nossa).

${ }^{5}$ Ver nos anexos a avaliação feita pelo próprio Castilho sobre o seu método.

${ }^{6}$ Matter. Visiteur dês écoles.

Recebido: fevereiro-16 Aprovado: março-16 